\title{
A proteomic view of isoproterenol induced cardiac hypertrophy: Prohibitin identified as a potential biomarker in rats
}

Debabrata Chowdhury ${ }^{1+}$, Anjana Devi Tangutur ${ }^{1 \dagger}$, Tarak Nath Khatua ${ }^{2}$, Priyanka Saxena ${ }^{3}$, Sanjay K Banerjee ${ }^{2^{*}}$ and Manika Pal Bhadra ${ }^{1 *}$

\begin{abstract}
Background: The present study aimed at using a proteomics based approach to: a) analyze and contrast the proteome of the healthy and isoproterenol induced hypertrophied hearts and b) identify potential biomarkers for diagnosis of cardiac hypertrophy.

Methods: Male Sprague Dawley (SD) rats were administered isoproterenol (ISO, $5 \mathrm{mg} / \mathrm{kg}$, sc, once daily) for 14 days to induce cardiac hypertrophy. There was a significant $(p<0.05)$ increase $(\sim 55 \%)$ in the heart weight to tail length ratio after 14 days of treatment and cardiac hypertrophy was evidenced by significant increase of $\beta-M H C$ and ANP, two indicative markers of cardiac hypertrophy, in the treated heart compared to that of control. Following confirmation of hypertrophy, 2DE of the tissue samples was done followed by MS/MS analysis of the protein spots to obtain a proteomic view for identification of novel biomarkers.

Results: Several important proteins were identified by proteomics analysis. They belong to the major functional categories such as cholesterol and protein metabolism, muscle contraction and development, transport, TCAcycle, ATP-biosynthesis, chaperone, signal transduction, DNA synthesis and ubiquitinisation. Careful examination of these protein spots by image analysis led to the successful identification of 7 differentially expressed proteins in the diseased sample. Further extension of this work for validation of differential expression of these proteins was also achieved by RTPCR and western blotting.

Conclusions: Our results demonstrate characteristic protein expression profile in control and hypertrophy condition in SD rats and also expand the existing knowledge on differentially expressed proteins in hypertrophy. The study signifies the importance of reduced expression of a novel protein such as Prohibitin (PHB) which may be associated with the cardiomyocytes growth and cardiac hypertrophy. However, further work is necessary to confirm the role of PHB in human heart and its potential role in diagnostic and therapeutic intervention in the clinic.
\end{abstract}

Keywords: Cardiac hypertrophy, Isoproterenol, Proteome analysis, 2D-gels, Differentially expressed proteins, Prohibitin

\section{Background}

Cardiac hypertrophy leading to heart failure is one of the major causes of morbidity and mortality in the world. Cardiac hypertrophy is characterized by a chronic physiological increase in cardiac muscle mass resulting from systolic or diastolic wall stress. This often occurs

\footnotetext{
* Correspondence: skbanerjee@iict.res.in; manika@iict.res.in

${ }^{\dagger}$ Equal contributors

${ }^{2}$ Division of Medicinal Chemistry and Pharmacology, Indian Institute of Chemical Technology, Uppal Road, Hyderabad 500607, India

${ }^{1}$ Centre for Chemical Biology, Indian Institute of Chemical Technology, Uppal Road, Hyderabad 500607, India

Full list of author information is available at the end of the article
}

normally during development, during pregnancy, and in response to sustained exercise [1]. However, if this condition persists, although initially compensatory for an increased workload, prolongation and prevalence of this process leads to congestive heart failure, arrhythmia, and sudden death [2]. It may also result from a number of pathological conditions such as hypertension, valvular disease, myocardial infarction and cardiomyopathy [3]. At the cellular level, cardiac hypertrophy is characterized by an increase in cell size, protein synthesis and reactivation of the fetal gene program finally leading to heart failure [4].

\section{Biomed Central}


Isoproterenol, a catecholamine, induced cardiac hypertrophy represents the most widely used model which mimics the sustained adrenergic stimulation and represents an important hallmark of the pathogenesis of maladaptive cardiac hypertrophy [5]. The activation of $\beta$-adrenergic signaling in turn induces in the heart many different mechanisms which contribute to the hypertrophic phenotype including enhanced protein synthesis, proto-oncogene expression, elevated oxidative stress, stimulation of mitogen activated protein kinases and phosphotidyl inositol-3 kinases [6]. Studies using transgenic mice with heart-specific overexpression of $\beta 1$ adrenergic receptors had increased cardiac contractility at a young age and also developed marked myocyte hypertrophy. Cardiac hypertrophy was followed by progressive heart failure with functional deficits similar to human heart failure [7].

While studies that focus on specific genes or pathways have provided insights over the years in human and animal models [8], integrative approaches are equally important in identifying multiple pathways or novel markers that are involved in the disease progression and mechanisms. The changes in protein expression in the myocardium are critical elements for understanding the molecular mechanisms of myocardial remodeling or identifying useful biomarkers for diagnostic purpose and therapeutic intervention. Two-dimensional gel electrophoresis coupled with mass spectrometry offers a key advantage of profiling of thousands of proteins in the biological samples. We therefore aimed to investigate the alterations in the proteome profile of healthy and isoproterenol induced hypertrophy in the SpragueDawley rats by proteomics approach using twodimensional gel electrophoresis in conjunction with matrix assisted laser desorption ionization - time of flight (MALDI-TOF) mass spectrometry to increase our understanding of the mechanistic pathways involved and to identify novel potential biomarkers for diagnosis and prognosis.

\section{Methods}

\section{Animals and treatment}

The experiments were initiated on 6-7 week old male Sprague Dawley (SD) rats weighing between $120-160 \mathrm{~g}$, obtained from National Institute of Nutrition (NIN), Hyderabad, India. The animals were housed in BIOSAFE, an animal quarantine facility of Indian Institute of Chemical Technology (IICT, Hyderabad, India), maintained at a temperature of $22 \pm 2^{\circ} \mathrm{C}$ and relative humidity of $50 \pm 15 \%$. Animals were acclimatized for a period of one week before the start of the study. A 12 hour dark/light cycle was maintained throughout the study. Air changes (15-16 cycles/hr) were maintained with $5 \mu$ HEPA filter. Rats had free access to food (pellet diet supplied from
National Institute of Nutrition, Hyderabad) and water ad libitum. The study protocols followed were in accordance with the guidelines of the Institutional Animal Ethics Committee of Indian Institute of Chemical Technology, Hyderabad and conform with the Guide for the Care and Use of Laboratory Animals published by the US National Institutes of Health (NIH Publication No. 85-23, revised 1985). For the development of hypertrophy all animals were weighed, and randomly divided into two groups: Control (Con: saline administration through subcutaneous route, 14 days, $\mathrm{n}=8$ ) and Hypertrophy (Hyp: isoproterenol administration through subcutaneous route, $5 \mathrm{mg} / \mathrm{kg} /$ day, 14 days, $\mathrm{n}=8$ ) [9]. Food and water intake was recorded daily. Body weight was taken at the start and end of 14 days. After sacrificing the rats, the heart tissues were carefully isolated and excised. Then hearts were washed three times with $1 \mathrm{X}$ PBS (pH-7.4) and stored in $-80^{\circ} \mathrm{C}$ freezer for future use.

\section{Estimation of heart weight/tail length ratio}

In each group, heart weight/tail length ratio was measured on the day of sacrifice as a parameter of cardiac hypertrophy. Tail length was measured by using a centimeter $(\mathrm{cm})$ scale. Heart weight $(\mathrm{gm})$ was measured after keeping the heart in ice cold saline and blotting out the heart with tissue paper [10].

\section{$\beta$-MHC and ANP gene expression as markers of cardiac hypertrophy}

Total RNA (DNAase free) was isolated from heart tissues using TRI REAGENT (Sigma, St. Louis, MO, USA). Reverse transcription was performed by using the MMLV reverse transcriptase kit (M6125H, Epicenter, WI, USA) for first-strand cDNA synthesis [11]. Real-time PCR was performed by using SYBR Green PCR Master Mix (2X) (Takara, Takara Bio. Inc., Japan) and following gene specific primers: forward primer, 5'-AGAGCAAAAGCAAA GGGTTTC-3' and reverse primer, 5'-GTGATGGTAC GAGATGGGCTA-3' for $\beta$-MHC and forward primer, 5' - AGCGAGCAGACCGATGAAG-3' and reverse primer, 5'-AGCCCTCAGTTTGCTTTTCA-3' for ANP. PCR amplification of RPL32 (16S Ribosomal protein L32) cDNA was performed as reference control by using the following primer pair: forward primer, $5^{\prime}$-AGATTCAAG GGCCAGATCCT $-3^{\prime}$ ' and reverse primer, 5'-CGATGGC TTTTCGGTTCTTA-3'.

\section{Protein extraction and quantitation}

Approximately $80 \mathrm{mg}$ of the heart tissue of control and cardiac hypertrophy samples were homogenized in a ratio of 1:20 with RIPA buffer in an electrical homogenizer followed by sonication with sonicator. The samples were then centrifuged at $14,000 \mathrm{rpm}$ for $30 \mathrm{~min}$ at $4^{\circ} \mathrm{C}$. The supernatant was collected and precipitated by standard 
TCA precipitation method. The pellet so obtained was solubilized in a sample buffer (8.0 M urea, 2\% CHAPS, $50 \mathrm{mM} \mathrm{DTT}$ ) at $4^{\circ} \mathrm{C}$. The protein concentration of these protein extracts was determined using the Bradford protein assay kit (Biorad, Hercules, CA, USA) according to the manufacturer's instructions using BSA as a standard. This protein sample could be used for 2-DE or stored in $-70^{\circ} \mathrm{C}$ until used. Biolyte $3 / 10$ ampholytes $(0.2 \%)$ and bromophenol blue (trace) were added to the protein sample prior to 2-DE (rehydration).

\section{One dimensional gel electrophoresis (1-DE)}

One dimensional SDS-PAGE was initially performed for preliminary proteomic profiling of control and hypertrophic heart samples according to Laemmli [12].

\section{Two dimensional gel electrophoresis (2-DE)}

Protein samples $(200 \mu \mathrm{g})$ were applied to an immobilized $\mathrm{pH}$ gradient (IPG) strip (7 cm, pH 4-7, Linear) (BioRad, Hercules, CA, USA) using a passive rehydration method $\left(16 \mathrm{~h}\right.$ of rehydration at $\left.20^{\circ} \mathrm{C}\right)$ according to the manufacturer's instructions. The IPG strips were then transferred to an isoelectric focusing (IEF) cell (BioRad, Hercules, CA, USA) and IEF was performed on a $7 \mathrm{~cm}$ gel strip according to the manufacturer's instructions. Prior to second dimension, the gel strips were equilibrated for 15 min twice in equilibration buffers I and II as previously described. The second dimension was performed using $12 \%$ SDS-PAGE at $80 \mathrm{~V}$. The gels were stained using the fast-coomassie staining method and scanned with a BioRad GS-800scanner. At least two independent runs were performed for each sample to ensure the accuracy of analyses. The 2D gel maps were analysed by the 'Progenesis same spots software' (Non-linear dynamics, Durham, NC, USA). The quantity of each spot in a gel was normalized as a percentage of the total quantity of all spots in that gel and evaluated in terms of optical density (OD). Only spots that showed consistent and significant differences were selected for MS analysis.

\section{In-gel trypsin digestion}

In-gel digestion of proteins was carried out using MS-grade Trypsin Gold (Promega, Madison, WI, USA) according to the manufacturer's instructions. Spots were cut out of the gel (1-2 mm diameter) using capillaries, and destained twice with $25 \mathrm{mM} \mathrm{NH}_{4} \mathrm{HCO}_{3} / 50 \%$ acetonitrile (ACN) at room temperature for $45 \mathrm{~min}$ in each treatment. This was followed by dehydration of the gels with $100 \%$ ACN for $5 \mathrm{~min}$. After dehydration and drying, the gels were preincubated in 10-20 $\mu$ l trypsin solution $(20 \mathrm{ng} / \mu \mathrm{l})$ for $1 \mathrm{~h}$. Then samples were added in adequate digestion buffer $\left(25 \mathrm{mM} \mathrm{NH}_{4} \mathrm{HCO}_{3} / 50 \% \mathrm{ACN}\right)$ to cover the gels and incubated overnight at $37^{\circ} \mathrm{C}$. Tryptic digests (peptides) were extracted twice with $50 \%$ ACN $/ 5 \%$ trifluoroacetic acid (TFA) for $30 \mathrm{~min}$ each time. The combined extracts were dried in a vacuum concentrator at room temperature. The extracted peptides were dissolved in $2.5 \mu \mathrm{l}$ of $50 \% \mathrm{ACN} /$ $0.1 \%$ TFA, and then $0.8 \mu \mathrm{l}$ of the digests was mixed with $0.8 \mu \mathrm{l} \mathrm{of} 5 \mathrm{mg} / \mathrm{ml}$ alpha-cyano-4-hydroxy-cinnamic acid (CHCA) (Applied Biosystems, Framingham, MA) in 50\% ACN/0.1\% TFA and spotted onto a MALDI target plate.

\section{Mass spectrometry (MALDI-TOF analysis)}

The samples were analyzed on a 4800 Proteomics Analyzer MALDI-TOF/TOF mass spectrometer (Applied Biosystems, Framingham, MA) working in positive ion reflector mode. Peptide mass fingerprint (PMF) of the tryptic digests was acquired in an automation mode. MS/ MS was performed in a data-dependent mode in which the top ten most abundant ions for each MS scan were selected for MS/MS analysis. The MS/MS data were acquired and processed using the global proteomics software and MASCOT was used to search the database. This software creates a peaklist from the raw spectra with a given threshold after removal of trypsin, polymer peaks, noise peaks and subjected to database interrogation for protein identification.

\section{Protein identification}

PMF data was interrogated for protein identification with NCBI database for Rattus using the mascot search engine (www.matrixscience.com). Searches were performed without constraining protein molecular weight or isoelectric point, with complete carbamidomethylation of cysteine, partial oxidation of methionine residues, and $1 \mathrm{missed}$ cleavage was also allowed in the search parameters. Proteins with probability-based Molecular Weight Search (MOWSE) scores exceeding their threshold $(P<0.05)$, number of matched ions, number of matching ions with independent MS/MS matches, percent protein sequence coverage, and correlation of gel region with predicted MW and PI were collectively considered for each protein identification. The peptide and fragment mass tolerance were set at $100 \mathrm{ppm}$, respectively.

\section{RNA isolation and Reverse Transcriptase PCR (RTPCR)}

Total RNA was isolated and Reverse transcriptasepolymerase chain reaction(s) were performed as described earlier in section 2.3. PCR was performed by using dNTPs Taq DNA polymerase, $\mathrm{MgCl}_{2}$ and specific primers according to the manufacturer's instructions (Takara Taq kit, Takara Bio. Inc., Japan). The primers for RTPCR analysis (Table 1) were designed using Primer 3 software (from published sequence information), avoiding regions of homology with other genes, for the following genes: MYL-2, MYL-3, PEBP-1, PHB, HSP60, ATP5 $\beta$ and Desmin. The PCR product was separated on a $2 \%$ agarose gel stained with ethidiumbromide. The gel images were captured using gel documentation system and 
Table 1 List of primer sequences for gene of interest

\begin{tabular}{|c|c|c|c|}
\hline Gene of interest & Primers & Sequence & $T_{m}$ \\
\hline \multirow[t]{2}{*}{ MYL2 } & Forward primer & 5'-GAAAGCCAAGAAGAGGTTAGAGG-3' & $55^{\circ} \mathrm{C}$ \\
\hline & Reverse primer & 5'-ATGGTGAGGAACACAGTGAAGTT-3' & \\
\hline \multirow[t]{2}{*}{ MYL3 } & Forward primer & 5'-AAGAGCTCAACTCCAAGATGATG-3' & $55^{\circ} \mathrm{C}$ \\
\hline & Reverse primer & 5'-TCTCTACCTCGTCTTCTGTCAGC-3' & \\
\hline \multirow[t]{2}{*}{ PEBP1 } & Forward primer & 5'-GTCATGAATAGACCAAGCAGCAT-3' & $57^{\circ} \mathrm{C}$ \\
\hline & Reverse primer & 5'-CTCATACACCAGCCAGACGTAG-3' & \\
\hline \multirow[t]{2}{*}{$\mathrm{PHB}$} & Forward primer & 5'-GGGTACAGAAGCCAATCATCTाT-3' & $55^{\circ} \mathrm{C}$ \\
\hline & Reverse primer & 5'-AATGCTGGTGTAGATACGAGGAA-3' & \\
\hline \multirow[t]{2}{*}{ HSP60 } & Forward primer & 5'-GCAGAGTTCCTCAGAGGTTGG-3' & $53^{\circ} \mathrm{C}$ \\
\hline & Reverse primer & 5'-CCCAGCAGCATCCAGTAAAG-3' & \\
\hline \multirow[t]{2}{*}{ Atp5b } & Forward primer & 5'-TGTATTTGCTGGTGTTGGTGA-3' & $53^{\circ} \mathrm{C}$ \\
\hline & Reverse primer & 5'-ACCTTGGAAGTGGCATCTITT-3' & \\
\hline \multirow[t]{2}{*}{ Desmin } & Forward primer & 5'-CTGATAGACGACCTGCAGAGG-3' & $55^{\circ} \mathrm{C}$ \\
\hline & Reverse primer & 5'-AAGGAATGCAATCTCCTCGTT-3' & \\
\hline \multirow[t]{2}{*}{ GAPDH } & Forward primer & 5'-TGGTGCTCAGTGTAGCCCAG-3' & $58^{\circ} \mathrm{C}$ \\
\hline & Reverse primer & 5'-GGACCTGACCTGCCGTCTAG-3' & \\
\hline
\end{tabular}

quantification of bands was performed using the Image J Software (NIH, Bethesda, MD, USA). For quantitative analysis, the signal intensity of each band was normalized with the GAPDH signals.

\section{Immunoblot analysis}

Total protein extraction and immunoblotting was performed as described previously [13]. Protein concentration was determined by Bradford method (Bio-Rad, Hercules, CA, USA). An equal amount $(20 \mu \mathrm{g})$ of protein of each of the samples under study was separated by sodium dodecyl sulfate polyacrylamide gel electrophoresis (SDS-PAGE). After electrophoresis, protein was transferred to PVDF membranes (GE Healthcare, USA). The membranes were then blocked in Tris-buffered saline Tween-20 (TBS-T; $10 \mathrm{mM}$ Tris, pH 7.5, $150 \mathrm{mM} \mathrm{NaCl}$, $0.05 \%$ Tween-20) and 5\% non-fat dry milk for $1 \mathrm{~h}$, and subsequently washed and incubated with primary antibodies in TBST with $2.5 \%$ non-fat dry milk at $4^{\circ} \mathrm{C}$ for overnight. The following polyclonal antibodies and titres were used: MYL2 (1:20,000, LS BioScience \#LSc105679), MYL3 (1 $\mu \mathrm{g} / \mathrm{ml}$, LS BioScience \# LSc107502), PEBP1 (0.02 $\mu \mathrm{g} / \mathrm{ml}$, LS BioScience \# LSb3247), PHB (2 $\mu \mathrm{g} / \mathrm{ml}, \mathrm{LS}$ BioScience \# LSc29731), Hsp60 (1:300, Abbiotec \#250700), ATPase $5 \beta$ (1:500, LS BioScience \# LS- C137091) and $\beta$ actin (1:1000, abcam \#ab8224). After washing with TBS-T, membranes were incubated with Goat Anti-Rabbit IgGHRP (1:1500 dilution, Santa Cruz Biotechnology, \# SC 2004) or Goat Anti-Mouse IgG-HRP (1:1500 dilution, Santa Cruz, \#2005) horseradish peroxidase conjugated secondary antibody with $2.5 \%$ non-fat dry milk at room temperature for $1 \mathrm{~h}$. After washing with TBS-T immunoreactions were visualized with a chemiluminescence detection kit (Prod No- 34080, Super signal ${ }^{\oplus}$ west Pico chemiluminescent substrate, Thermo Scientific). Then the blots were exposed to $\mathrm{X}$ - ray film (Hyperfilm ECL, GE Healthcare, USA) and developed by using a hyper processor (Model -SRX -101A, Amershan Biosciences). Gel stained with coomassie blue served as an equal loading control. Quantification of band intensity was performed using the Image J Software $(\mathrm{NIH}$, Bethesda, MD, USA). For quantitative analysis, the signal intensity of each of the protein was normalized with the corresponding $\beta$-actin signal.

\section{Statistical analysis}

All values were expressed as mean \pm SEM. Data were statistically analyzed using student unpaired ' $\mathrm{t}$ ' test for group wise comparison. Significance was set at $\mathrm{P} \leq 0.05$.

\section{Results}

\section{Development of hypertrophy in SD rats}

Isoproterenol (5 $\mathrm{mg} / \mathrm{kg} /$ day) was administered through subcutaneous route for 14 days to induce cardiac hypertrophy. There was 55\% increase in heart weight and tail length ratio observed in hypertrophy (Hyp) group compared to control (Con) group (Figure 1A \& B). The mRNA levels of hypertrophic marker, $\beta-\mathrm{MHC}$ and ANP were analyzed by Real time PCR which showed elevated levels of this mRNA in Hyp heart compared to Con heart (Figure $1 C$ \& D). 
Figure 1 Chronic administration of isoproterenol caused cardiac hypertrophy in SD rats. (A) Images of whole heart from control and isoproterenol-treated SD rat. (B) Heart weight and tail length ratio from control and isoproterenol-treated SD rat. (C) $\beta$ MHC gene expression from both control and hypertrophic heart measured by Real-time PCR. (D) ANP gene expression from both control and hypertrophic heart measured by Real-time PCR. Data shown as mean $\pm \mathrm{SEM}^{*} \mathrm{p} \leq 0.05$ versus control.

\section{Proteomic assessment of cardiac hypertrophy}

Using the above hypertrophy data as guide, we proceeded to examine the global protein complement of left ventricular muscle isolated from control and hypertrophied heart to identify the proteins exhibiting altered abundance as a function of disease progression. For preliminary comparison of the expression levels of total protein extracted from the left ventricle of control and hypertrophy heart samples, we performed one dimensional gel electrophoresis. Additional file 1 (Additional material) shows the representative 1-DE gel image of proteins isolated from cardiac tissue of control and hypertrophic SD rats (Additional file 1: Figure S1). However, since each band in $1 \mathrm{D}$ can be a mixture of one, two or more proteins, the results of MALDI-TOF MS analysis indicated protein identification with low MOWSE scores (data not shown). Therefore, to further improve the resolution of separation and identification of differentially expressed proteins in control and hypertrophic samples we carried out two dimensional gel electrophoresis. Proteins $(200 \mu \mathrm{g})$ extracted and estimated as described in materials and methods for the chosen samples, were separated in the first dimension by isoelectric focusing on strip gel with $\mathrm{pI}$ range 3-10 and in the second dimension using 12.0\% SDS-PAGE followed by Fast coomassie staining method. 2-DE of the samples on a 3-10 pI IPG strip indicated better resolution of proteins in the pI range of 4-7 and therefore 2DE was carried out using IPG strips with $\mathrm{pI} 4-7$. The protein profile of control and hypertrophic heart was compared. The protein spots which were differentially expressed in both the samples are indicated in Figure 2. These bands were picked up and digested by in-gel trypsin digestion. This was followed by identification with MALDI-TOF MS. The peptides mass peaks were compared with those in the NCBI database (Figure 3).

\section{The functional cardiac proteome}

We initially focused on identifying the proteins of the cardiac proteome from the control sample. The conditions used for profiling 2-D gel allowed access to a total of $\sim 60$ visible proteins. All these spots were marked in the control sample and in-gel trypsin digestions followed by mass spectrometry were performed for subsequent identification. Figure 2 shows the representative 2-D gel of proteins isolated from cardiac tissue of control SD 


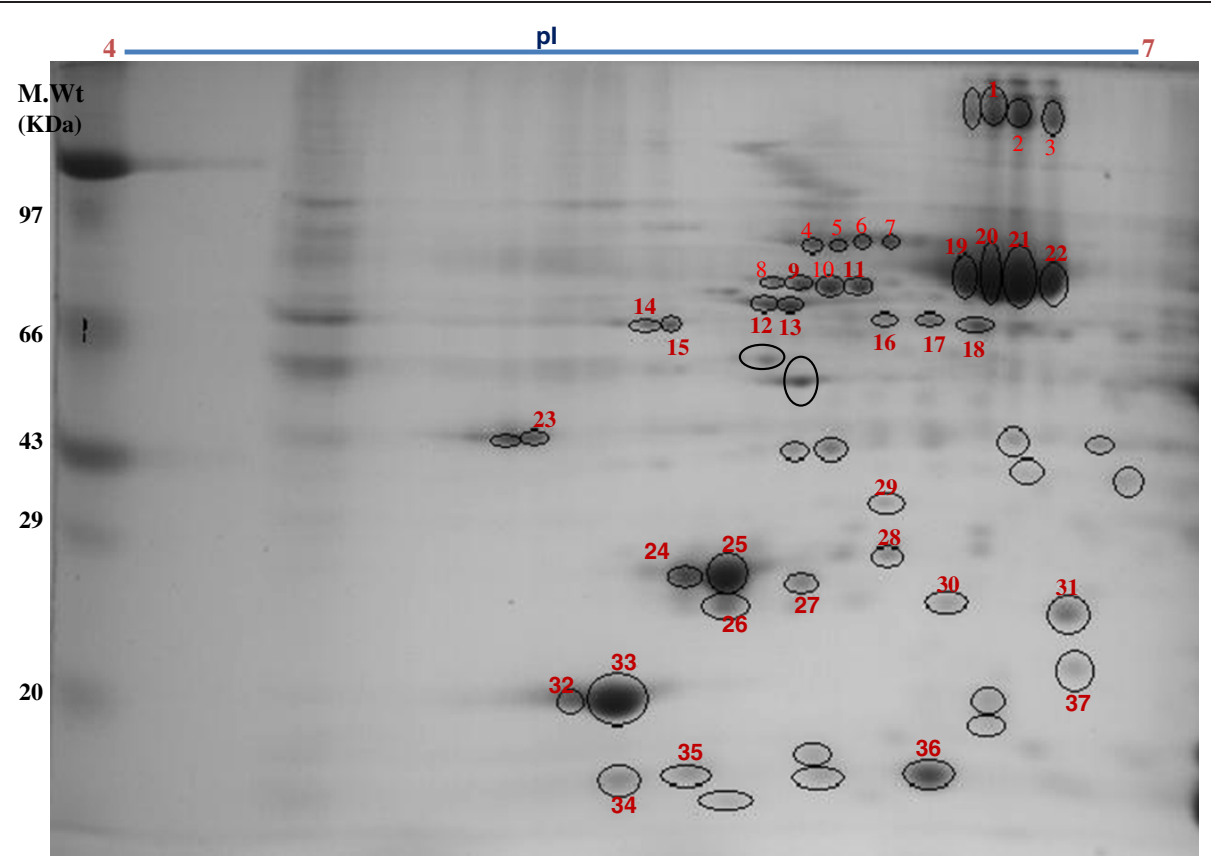

Figure 2 2-DE gel analysis of proteins extracted from the cardiac tissue of SD rats. In the first dimension, $200 \mu \mathrm{g}$ of protein was loaded on a $7 \mathrm{~cm}$ IPG strip with a linear gradient of $\mathrm{pH}$ 4-7. In the second dimension, 12\% SDS -PAGE gels were used. Proteins were visualized by fast coomassie staining. All the differentially expressed spots were marked and identified by MS-analysis. Sizes of the molecular mass markers (in KDa) are indicated.

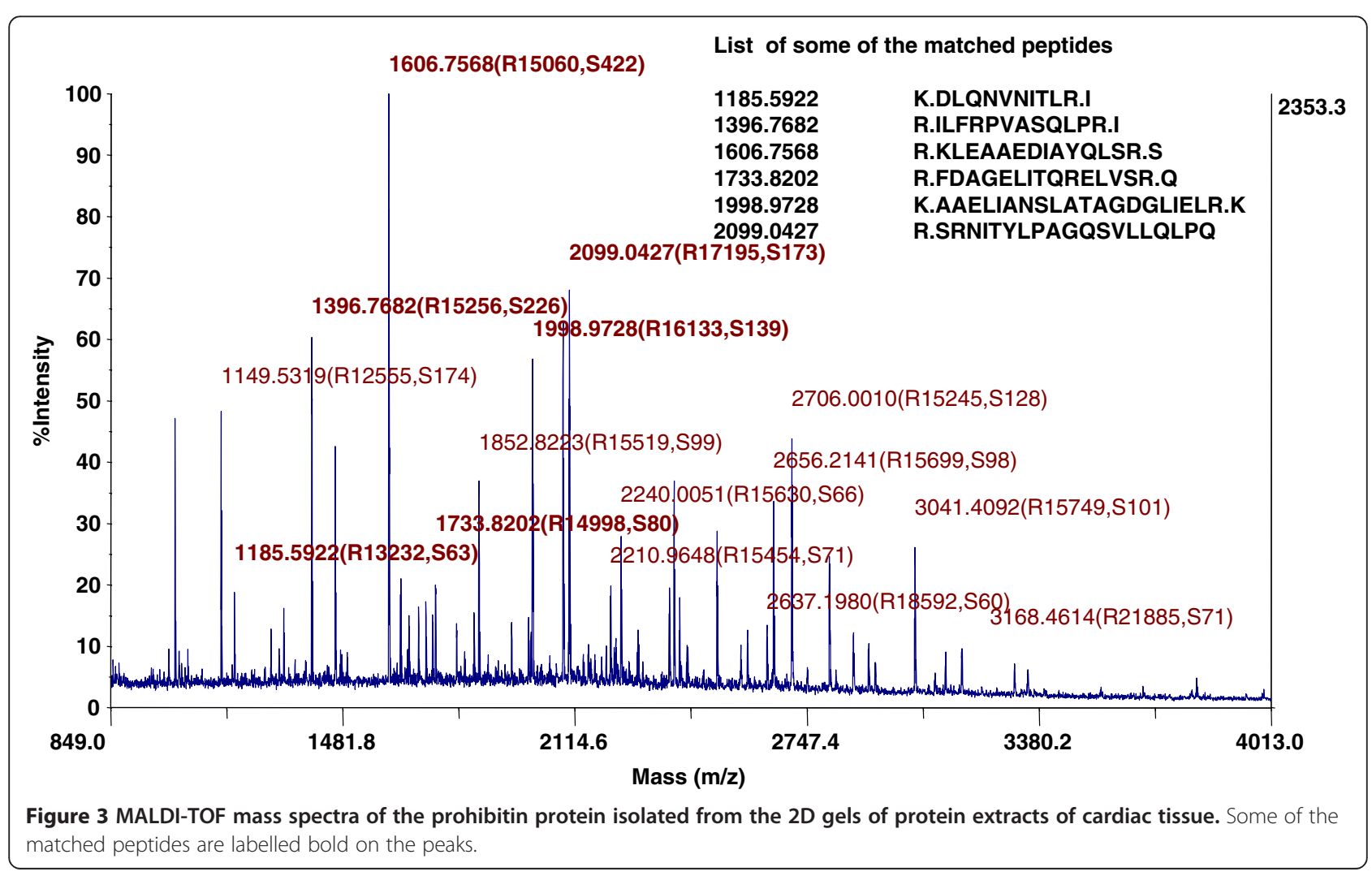


Table 2 List of proteins identified from 2D gels of protein extracts of cardiac tissue

\begin{tabular}{|c|c|c|c|c|c|c|c|}
\hline Spot no. & Category & Accession no. & Protein name & $\begin{array}{l}\text { No. of matched } \\
\text { peptides }\end{array}$ & $\begin{array}{l}\text { Protein } \\
\text { score }\end{array}$ & M.Wt & $\mathrm{pl}$ \\
\hline 1. & Uncharacterised & gi|55628 & Unnamed protein product [rattus norvegicus] & 14 & 75 & 70670 & 6.09 \\
\hline 2. & Transport & gi|149033753 & Albumin, isoform cra_a [rattus norvegicus] & 13 & 78 & 53060 & 6.72 \\
\hline 3. & Transport & gi|149033753 & Albumin, isoform cra_a [rattus norvegicus] & 10 & 87 & 53060 & 6.72 \\
\hline \multirow[t]{2}{*}{4.} & \multirow[t]{2}{*}{ Chaperone } & \multirow{2}{*}{$\begin{array}{l}\text { gi } 1000439+\text { gi } \\
178847300\end{array}$} & \multirow{2}{*}{$\begin{array}{l}\text { grp75 [rattus sp.] chain a, crystal structure of the } \\
70-k d a \text { heat shock cognate protein }\end{array}$} & \multirow[t]{2}{*}{31} & \multirow[t]{2}{*}{110} & 73984 & 5.87 \\
\hline & & & & & & +59895 & 5.91 \\
\hline 5. & Uncharacterised & gi|149041392 & rcg57965, isoform cra_b & 9 & 65 & 48623 & 6.16 \\
\hline 6. & Signal transduction & gi|149022678 & $\begin{array}{l}\text { Mitogen activated protein kinase } 8 \text { interacting } \\
\text { protein, isoform cra_d }\end{array}$ & 6 & 47 & 75419 & 4.73 \\
\hline 7. & Chaperone & gi|1000439 & grp75 [rattus sp.] & 10 & 72 & 73984 & 5.87 \\
\hline 8. & $\begin{array}{l}\text { Muscle contraction and } \\
\text { development }\end{array}$ & gi|149058891 & Calpastatin, isoform cra_a & 4 & 43 & 20886 & 5.20 \\
\hline 9. & Uncharacterised & gi|1334284 & Unnamed protein product & 8 & 47 & 58061 & 5.35 \\
\hline 10. & Chaperone & gi|56383 & Heat shock protein (hsp60) precursor & 17 & 90 & 61098 & 5.91 \\
\hline 11. & Uncharacterised & gi|1334284, & Unnamed protein product & 13 & 74 & 58061 & 5.35 \\
\hline 12. & $\begin{array}{l}\text { Muscle contraction and } \\
\text { development }\end{array}$ & gi|11968118 & Desmin & 7 & 61 & 53481 & 5.21 \\
\hline 13. & $\begin{array}{l}\text { Muscle contraction and } \\
\text { development }\end{array}$ & gi|11968118 & Desmin [rattus norvegicus] & 29 & 226 & 53481 & 5.21 \\
\hline 14. & ATP biosynthesis & gi|1374715 & ATP synthase beta subunit & 32 & 159 & 51171 & 4.92 \\
\hline 15. & ATP biosynthesis & gi|1374715 & ATP synthase beta subunit & 22 & 140 & 51171 & 4.92 \\
\hline 16. & Uncharacterised & gi|293344961 & predicted: hypothetical protein & 7 & 45 & 32379 & 8.55 \\
\hline 17. & TCA cycle & gi|149025181 & $\begin{array}{l}\text { Dihydrolipoamide s-succinyltransferase } \\
\text { (e2 component of 2-oxo-glutarate comp. }\end{array}$ & 7 & 55 & 21198 & 6.92 \\
\hline 18. & TCA cycle & gi|149025181 & $\begin{array}{l}\text { Dihydrolipoamide s-succinyltransferase } \\
\text { (e2 component of 2-oxo-glutarate comp. }\end{array}$ & 5 & 55 & 21198 & 6.92 \\
\hline 19. & Transport & gi|149033753 & Albumin, isoform cra_a & 13 & 87 & 53060 & 6.72 \\
\hline 20. & Transport & gi|149033753 & Albumin, isoform cra_a & 14 & 83 & 53060 & 6.72 \\
\hline 21. & Transport & gi|149033753 & Albumin, isoform cra_a & 13 & 82 & 53060 & 6.72 \\
\hline 22. & Transport & gi|149033753 & Albumin, isoform cra_a & 13 & 78 & 53060 & 6.72 \\
\hline 23. & Uncharacterised & gi|149066551 & rcg59557 & 5 & 54 & 12861 & 9.18 \\
\hline 24. & Uncharacterised & gi|149063941 & rcg23467, isoform cra_a & 5 & 51 & 223560 & 5.59 \\
\hline 25. & $\begin{array}{l}\text { Muscle contraction and } \\
\text { development }\end{array}$ & gi|6981240, & Myosin light chain 3 & 16 & 97 & 22256 & 5.03 \\
\hline 26. & $\begin{array}{l}\text { Muscle contraction and } \\
\text { development }\end{array}$ & gi|6981240, & Myosin light chain 3 & 13 & 55 & 22256 & 5.03 \\
\hline 27. & $\begin{array}{l}\text { Protein, cholesterol } \\
\text { metabolism }\end{array}$ & gi|149063506 & $\begin{array}{l}\text { Phosphatidylethanolamine binding protein } 1 \text {, } \\
\text { isoform cra_a }\end{array}$ & 7 & 42 & 10775 & 6.26 \\
\hline 28. & $\begin{array}{l}\text { Protein, cholesterol } \\
\text { metabolism, transport }\end{array}$ & gi|6978515 & Apolipoprotein a-i preproprotein & 3 & 43 & 30100 & 5.52 \\
\hline 29. & DNA synthesis & gi|6679299 & Prohibitin & 5 & 141 & 29859 & 5.57 \\
\hline 30. & Uncharacterised & gi|149054764 & rcg33654, isoform cra_d & 14 & 48 & 16329 & 5.45 \\
\hline 31. & Ubiquitinisation & gi|149016294 & F-box only protein 36 (predicted), isoform cra_c & 4 & 40 & 9895 & 9.52 \\
\hline 32. & $\begin{array}{l}\text { Muscle contraction and } \\
\text { development }\end{array}$ & gi|127167 & $\begin{array}{l}\text { Myosin regulatory light chain 2, ventricular/ } \\
\text { cardiac muscle isoform }\end{array}$ & 6 & 120 & 18868 & 4.86 \\
\hline 33. & $\begin{array}{l}\text { Muscle contraction and } \\
\text { development }\end{array}$ & mlrv_rat & $\begin{array}{l}\text { mlrv_rat, myosin regulatory light chain 2, } \\
\text { ventricular/cardiac muscle isoform }\end{array}$ & 12 & 169 & 18868 & 4.86 \\
\hline
\end{tabular}


Table 2 List of proteins identified from 2D gels of protein extracts of cardiac tissue (Continued)

\begin{tabular}{|c|c|c|c|c|c|c|c|}
\hline 34. & Uncharacterised & gi|293349387 & Predicted: hcg2036631-like & 23 & 54 & 51880 & 9.69 \\
\hline 35. & $\begin{array}{l}\text { Protein,cholesterol } \\
\text { metabolism }\end{array}$ & gi|149043202 & Calpain 9 & 7 & 43 & 51956 & 5.79 \\
\hline 36. & Transport & gi|13162363 & Fatty acid-binding protein, heart & 9 & 96 & 14766 & 5.91 \\
\hline 37. & $\begin{array}{l}\text { Muscle contraction and } \\
\text { development }\end{array}$ & gi|20302069 & Heat shock protein beta- 6 & 9 & 68 & 17551 & 6. \\
\hline
\end{tabular}

rats where the picked and identified protein spots are indicated. A total of 37 proteins were identified (Additional file 2: Figure S2 \& Table 2) with significant score. The functional classification of the identified proteins resulted in the following major categories: Cholesterol and protein metabolism, muscle contraction and development, transport, TCA cycle, ATP-biosysnthesis, chaperone, signal transduction, DNA synthesis and ubiquitinisation. Figure 4A shows the pie chart grouping of the identified proteins into functional classes annotated using the expasy database (http://expasy.org/uniprot). Figure $4 \mathrm{~B}$ shows the pie chart grouping of the identified proteins based on their cellular localization.

\section{Comparative proteome profiling of control and hypertrophic heart tissues}

In an effort to gain insight into the molecular mechanisms underlying the pathogenesis of cardiac hypertrophy, we also performed a comparative analysis of the protein expression profiles of control and cardiac hypertrophy samples of rats by image analysis of $2 \mathrm{D}$ gels using 'progenesis same spots software'. This resulted in the identification of several differentially expressed protein spots between control and cardiac hypertrophy gels. These differentially expressed proteins of cardiac hypertrophy are shown in Figure 5 and listed in Table 2. These include fatty acid binding protein, heart (H-FABP) (spot no. 36), phophatidylethanolamine binding protein (PEBP1) (spot no. 27), apolipoprotein A-1 preprotein (spot no.28), calpain 9 (spot no.35), heat shock cognate protein, $70 \mathrm{kda}$ (HSP70) (spot no.4), heat shock protein 60 precursor (HSP60) (spot no. 10) and heat shock protein B6 (HSPB6) (spot no.37), mitogen activated protein kinase 8 interacting protein (isoform CRA-d) (spot no.6), myosin light chain 3 (MYL3) (spot no.24,25), myosin light chain 2 (MYL2) (spot no. 32,33), desmin (spot no.12,13), dihydrolipoamide succinyltransferase (spot no.18), F-box only protein 36 (isoform CRA_c) (spot no. 31), ATP synthase $\beta$-subunit (ATP5 $\beta$ ) (spot no.14,15) and prohibitin (PHB) (spot no. 29) (Figure 5).

\section{Gene expression analysis for the validation of proteomics data}

We attempted further validation of seven differentially expressed proteins by semiquantitative RTPCR to check the mRNA expression levels at the transcriptional level (Figure 6). There was a significant $(\mathrm{p}<0.05)$ decrease in levels of MYL2, MYL3, PEBP1, PHB and ATP5 $\beta$ gene levels in hypertrophy (Hyp) group compared to control (Con). Although, there was an increase in HSP60 and decrease in Desmin gene expression levels observed in the hypertrophy (Hyp) group compared to Control (Con), these changes were not significant. GAPDH was used as an internal control for normalization in the gene expression studies.

\section{Immunoblot analysis for the validation of the proteomics data}

Immunoblot analysis was performed for these differentially expressed proteins with specific antibodies to validate the levels obtained from 2-DE data. $\beta$ - actin was used as a reference for comparison of protein levels. There was no change in HSP60 expression observed in hypertrophy (Hyp) group compared to control (con). However, significant decrease in protein levels was observed for MYL2, ATP5 $\beta$ and PHB compared to control (Figure 7). Although there was a decrease in protein levels for both MYL3 and PEBP1 in Hyp group compared to Con but it was not significant.

\section{Discussion}

Several attempts have been tried on cardiac tissues to disclose underlying molecular pathogenesis of cardiac hypertrophy in different disease models [14]. However, there is no proteomic study to identify important targets or biomarkers from isoproterenol-induced hypertrophy heart. To the best of our knowledge, this study considerably resolves the proteome of healthy and diseased hearts to investigate and understand the complex mechanism of isoproterenol induced cardiac hypertrophy. Table 2 provides a summary of the list of proteins identified from the 2D gels of cardiac tissue of SD rats. By this approach we were also able to identify several proteins which were specifically and significantly altered in cardiac hypertrophy.

In the present study, we demonstrate that isoproterenol induced cardiac hypertrophy effects at the molecular level, affecting the cardiac protein expression profiles in SD rats. The protein(s) of the following functional categories are altered, the expression of which were further validated by 
A Functional classification of the identified proteins

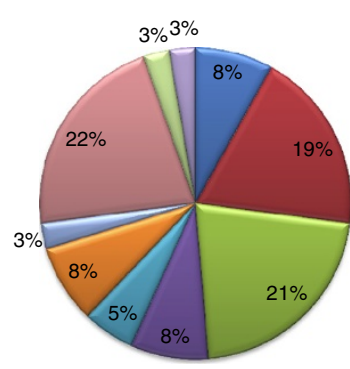

Protein, cholestero metabolism Muscle contraction and development ⿶Transport

- TCA cycle

ATP biosynthesis

घChaperon

⿶Signal transduction

⿶Uncharacterised

$\square$ DNA synthesis

๑Ubiquitinisation
B Classification of the identified proteins based on their localization

$$
\begin{array}{ll}
\text { - Mitochondria } & \text { - Cytoplasm } \\
\text { - Secreted } & \text { - Uncharacterised }
\end{array}
$$

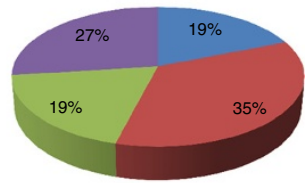

Figure 4 Classification of identified proteins based on their function and cellular localization. (A) Pie chart grouping the identified proteins in functional classes annotated using expasy database (http://expasy.org/uniprot). (B) Pie chart grouping the identified proteins based on their cellular localization.

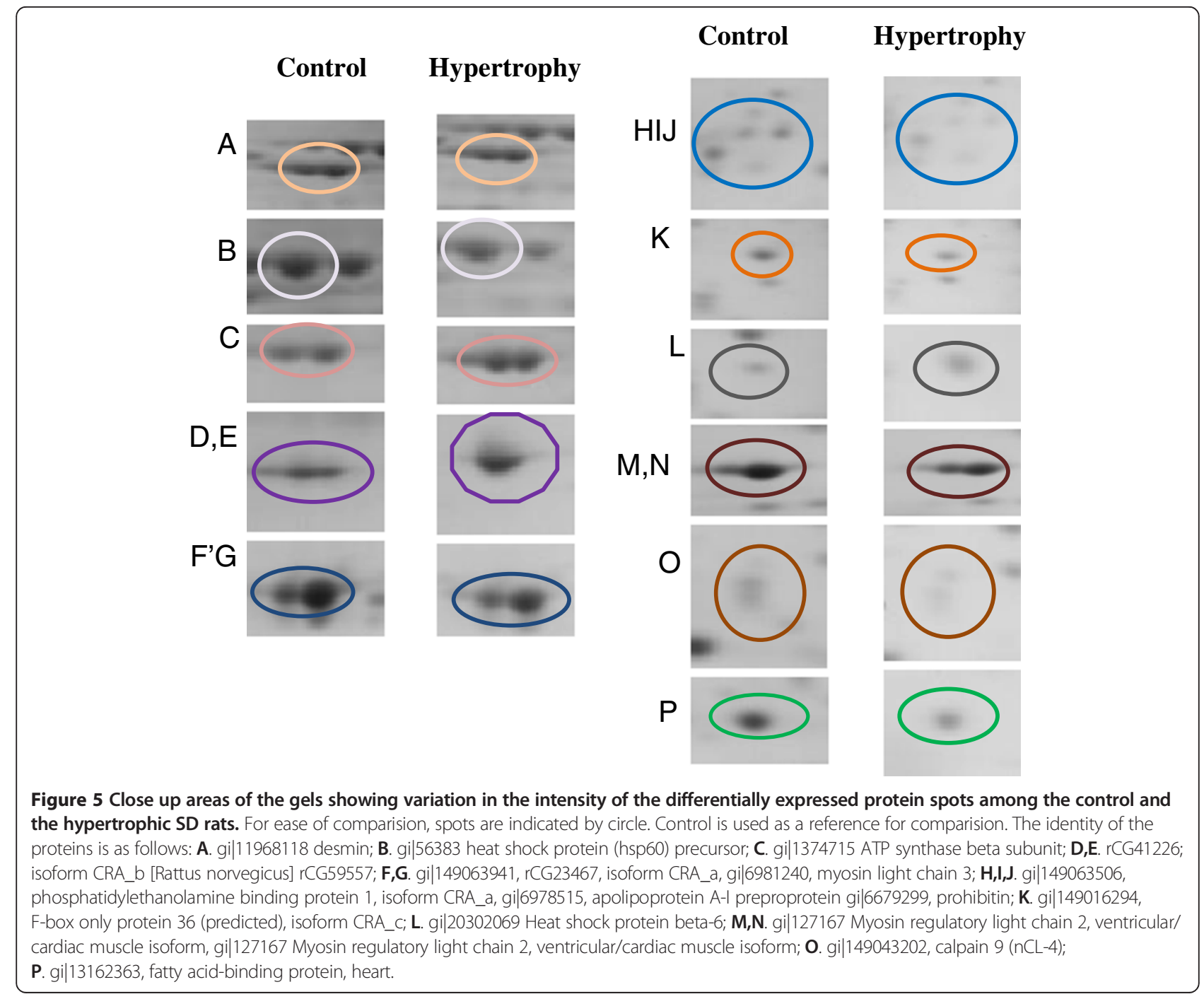




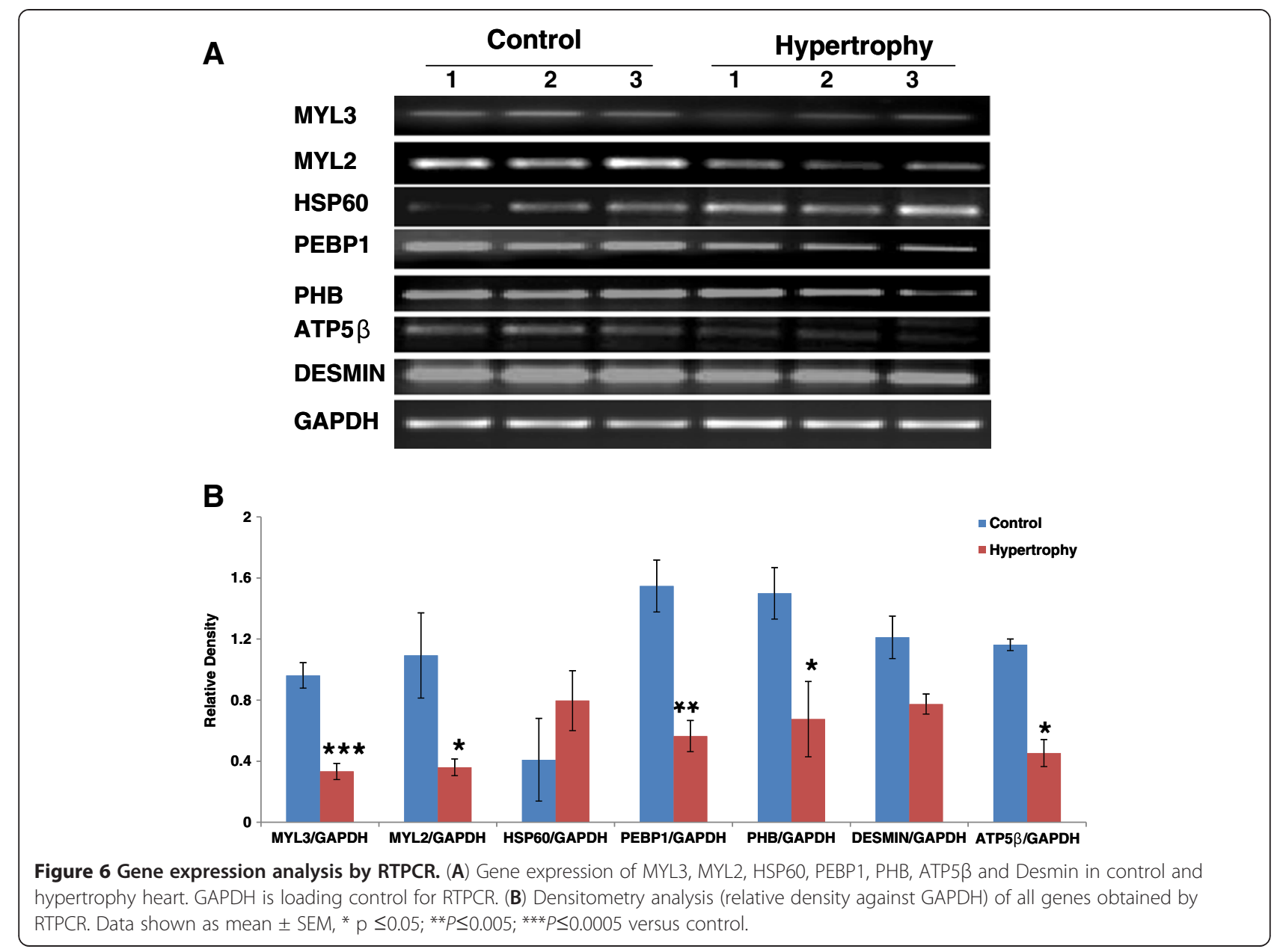

RTPCR and western blotting: (i) Muscle contraction and development, (ii) Transport, (iii) Chaperones, (iv) ATP biosynthesis, (v) DNA synthesis. An intriguing question which rises following this study is whether this differential protein expression analysis might reveal some novel plausible candidates which could act as master regulators responsible for hypertrophy. Identification of novel target is critical to develop new class of drug molecules to modulate or alter the protein function in hypertrophy. Therefore, we initially provide details of proteins which were differentially expressed in our study of isoproterenolinduced hypertrophy and the expression of which are in consistence with the prior studies in other models (such as endothelin-1(ET-1) or leukemic inhibitory factor (LIF) induced hypertrophy models or other models of heart failure, strokes, myocardial infarction MI(s) etc.), followed by detailed description of protein prohibitin, which we speculate as a novel potential biomarker in isoproterenolinduced hypertrophy.

Concerning the category (i), we observed a reduction in MYL2 and MYL3 protein levels in isoproterenol-induced hypertrophy compared to control indicating cardiac damage. Myosin light chain 2 (MYL2), also known as myosin regulatory light chain is implicated in myosin ATPase activity and smooth muscle contraction. Mutations in MYL2 are well associated with familial cardiac hypertrophy [15]. Similarly, MYL3 is associated with cardiac microfibrillar assembly and heart contraction [16]. Changes in the levels of myosin light chain 2 and myosin light chain 3 (MYL2 and MYL3) proteins upon isoproterenol treatment, observed in our study are consistent with the earlier observations of heart failure or cardiomyopathy [17]. Down regulation of MYL2 was observed in human heart failure tissues and this data suggested that MYL2 may play a role in the development and progression of chronic heart failure [18]. Serum proteomic signature of human chagasic patients, (caused by infection with trypanosoma cruzi) where there is a decline in heart function, revealed decrease in MYL 2 levels [19]. Desmin is another protein of category I, which along with other proteins acts as a major stress bearing element in the sarcomere. The levels of this protein are reported to increase along with other cytoskeletal proteins such as tubulin, vinculin and vimentin under conditions of idiopathic 


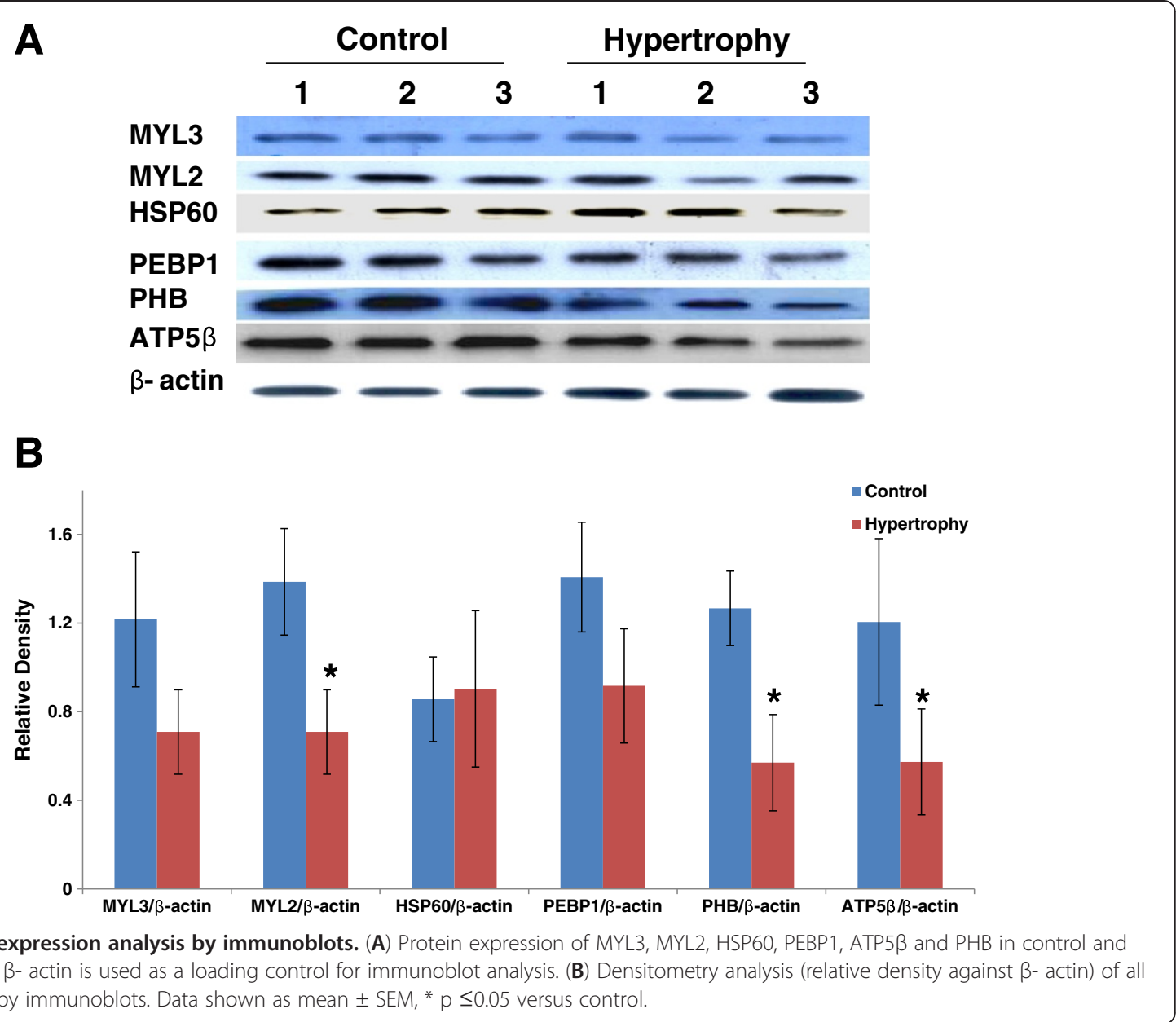

dilated cardiomyopathy [20] and also during transition from compensated ventricular hypertrophy to heart failure [21]. However, in contrast to other studies we observed a decrease in desmin gene expression levels in isoproterenolinduced hypertrophy. This might be due to different type of cardiac hypertrophy model and early stages of heart failure.

Category (ii) includes transport proteins such as fatty acid binding protein, Heart (H-FABP), which interestingly showed decrease in the levels in the hypertrophic heart in our 2D gels. H-FABP is known to be involved in fatty acid beta oxidation, intracellular utilization of fatty acids and long chain fatty acid transporter activity. It has been earlier reported as a serum marker for the early diagnosis of stroke as well as acute and chronic myocardial infarctions. HFABP levels are significantly elevated above their threshold level within 3hrs of myocardial infarction and subsequently return to normal levels within 12-24 hrs [22]. However coronary ligation (MI and ramipril treatment) decreased the protein expression of H-FABP in the left ventricular tissue compared to sham group. In addition, ramipril (known for beneficial role in cardiovascular diseases) treatment caused an increase in $\mathrm{H}-\mathrm{FABP}$ of rabbit $\mathrm{LV}$ with $\mathrm{MI}$ indicating that ramipril may modulate the expression of $\mathrm{H}-\mathrm{FABP}$ by post translational modifications [23].

The Heat shock proteins (HSP60, HSP70 and HSPD1), representing category (iii) increased in the isoproterenolinduced disease model in comparison to control in the present study. Interestingly, these proteins are known to change in abundance during cardiac hypertrophy in vitro and have also been shown to change in human/animal models of hypertrophy [24]. Proteomic analysis revealed significant elevation of heat shock protein 70 in patients with chronic heart failure due to arrhythmogenic right ventricular cardiomyopathy (ARVC). Results of the study indicated that elevated HSP70 levels as the common feature of heart failure due to ARVC, DCM, and ICM suggesting that HSP70 may be used as a biomarker for the presence of heart failure due to cardiomyopathies of different etiologies and may hold diagnostic/prognostic potential in clinical practice [25]. Also, proteomic analysis in congestive heart failure revealed significant alternations of cardiac small heat shock protein expression [26].

Concerning the effect of Isoproterenol on ATP biosynthesis (category IV), the energetics of hypertrophy (LV) 
and heart failure have been extensively studied. In heart failure, abnormalities are found in myocardium relating to substrate use, oxidative phosphorylation, and the high energy transfer mechanism involving creatine. Consisent with this we observed a decrease in ATP-synthase $5 \beta$ levels in hypertrophic heart compared to control heart. However, cardioprotection against hypobaric hypoxia showed elevated levels of ATP-synthase $5 \beta$ suggesting improvement in mitochondrial energy metabolism [27].

In the present study, we identified prohibitin, a mitochondrial protein, as differentially expressed and decreased significantly in hypertrophic heart compared to control (Figure 5 and Figure 6). Prohibitins are ubiquitous, evolutionarily conserved proteins that are mainly localized in mitochondria [28]. Although the accumulating evidence suggests that prohibitins are localised primarily within mitochondria, their function remains poorly understood. Studies in different organisms have provided significant insights into the role of the prohibitin complex in mitochondrial biogenesis and metabolism [29]. Mitochondrial dysfunction is believed to be involved in the process of free radical generation, leading to hypertrophy and heart failure [30]. Isoproterenol-induced cardiac injury is associated with mitochondrial disorder affecting one or more of the respiratory redox chain [31]. The heart tissues, which rely most extensively on aerobic metabolism, are most severely affected by mitochondrial defects. Therefore, attention has been recently focused towards investigation of mitochondrial function and its biogenesis.

To our knowledge, this study provides the first experimental evidence for decreasing levels of prohibitin (PHB) expression in hypertrophic rat heart. The expression of PHB1 is also down-regulated after induction of oxidative stress in epithelial cells as well as in diseases linked to enhanced reactive oxygen species (ROS) such as ulcerative colitis and Crohn's disease [32] Oxidative stress has been identified as one of the key contributing factors in the progression and development of cardiac hypertrophy. Several research articles support the fact that ROS generated from mitochondria cause cardiac hypertrophy [9]. Although increased ROS and mitochondrial dysfunction are associated with cardiac hypertrophy, it is not known if PHB is able to collectively control these events or have an impact on cardiac hypertrophy. Knockdown of prohibitin (PHB1) in endothelial cells increases mitochondrial production of reactive oxygen species via inhibition of complex I [33]. It is possible that decreased expression of PHB in hypertrophy heart might be responsible for mitochondrial dysfunction and oxidative stress. Evidence of increased oxidative stress in isoproterenolinduced cardiac hypertrophy was reported earlier [34].

Therefore, we hypothesize that the reduced expression of PHB might be responsible for mitochondrial dysfunction and increased oxidative stress in isoproterenol-induced cardiac hypertrophy. Future treatment strategy can be initiated to increase mitochondrial PHB by pharmacological and/or therapeutic agents. Alternatively, PHB can also be used as a potential biomarker for stress induced cardiac hypertrophy.

\section{Conclusions}

The successful use of multiple techniques, including 2-DE and MALDI-TOF-MS demonstrates that proteomic analysis provides appropriate means for identifying cardiac biomarkers in hypertrophy. The analysis of changes in myocardial protein expression may serve as source of possible biomarkers for hypertrophic cardiac damage. Our data offer new insights into understanding the cellular and molecular mechanisms that underlie cardiac dysfunction in cardiac hypertrophy induced by "a catecholamine". The present study identifies alteration in the prohibitin levels, as a key actor and contributor to the progression of cardiac hypertrophy and heart failure. Data obtained in experimental animals must be extrapolated to the clinical arena for further investigation. Nevertheless, the findings from the present study show that prohibitin could be useful to predict the therapeutic response to established and novel therapies for the prophylaxis of cardiac hypertrophy and subsequent heart failure in cardiac patients.

\section{Additional files}

Additional file 1: Figure S1. 1-D 10\% SDS-PAGE of control and hypertrophic heart. Approx $20 \mu \mathrm{g}$ of protein from control (C1, C2, C3) and hypertrophic samples $(\mathrm{H} 1, \mathrm{H} 2, \mathrm{H} 3)$ was separated on SDS PAGE and analyzed for identification of differentially expressed protein(s).

Additional file 2: Figure S2. Protein profiling of the control and hypertrophic heart by two dimensional (2D) gel electrophoresis. Proteins were separated on 2D PAGE and visualized by fast coomassie staining. Labelled spots correspond to differential proteins analyzed and identified by MS-analysis.

\section{Abbreviations}

2DE: 2 Dimensional Gel Electrophoresis; SD: Sprague Dawley; PMF: Peptide mass fingerprinting; MS: Mass Spectrometry; MALDI: Matrix-assisted laser desorption/ionization; TOF: Time of flight.

\section{Competing interests}

The authors declare that they have no conflict of interests.

\section{Authors' contributions}

DC and TAD designed and carried out most of the experiments, data analysis and analyzed the proteomic data. TNK developed and confirmed the animal models of hypertrophy; PS did the MS analysis of samples and provided the mass spectrometry data. SKB guided the development of animal models. SKB and MPB conceived the study, participated in designing and coordinated in drafting the manuscript. All authors read and approved the final manuscript.

\section{Acknowledgments}

This work was mainly supported by Ramalingaswami fellowship funds to SKB from Department of Biotechnology (DBT) and funds from Council of Scientific and Industrial Research (UNDO and SMiLE). 


\section{Author details}

${ }^{1}$ Centre for Chemical Biology, Indian Institute of Chemical Technology, Uppal Road, Hyderabad 500607, India. ${ }^{2}$ Division of Medicinal Chemistry and Pharmacology, Indian Institute of Chemical Technology, Uppal Road, Hyderabad 500607, India. ${ }^{3}$ Centre for Cellular and Molecular Biology, Uppal Road, Hyderabad 500607, India.

Received: 14 December 2012 Accepted: 1 May 2013

Published: 24 May 2013

\section{References}

1. Lorell BH, Carabello BA: Left ventricular hypertrophy: pathogenesis, detection, and prognosis. Circulation 2000, 102:470-479.

2. Yung CK, Halperin VL, Tomaselli GF, Winslow RL: Gene expression profiles in end-stage human idiopathic dilated cardiomyopathy: altered expression of apoptotic and cytoskeletal genes. Genomics 2004, 83:281-297.

3. Berenji K, Drazner MH, Rothermel BA, Hill JA: Does load-induced ventricular hypertrophy progress to systolic heart failure? Am J Physiol Heart Circ Physiol 2005, 289:H8-H16.

4. Frank D, Kuhn C, Brors B, Hanselmann C, Lüdde M, Katus HA, Frey N: Gene expression pattern in biomechanically stretched cardiomyocytes: evidence for a stretch-specific gene program. Hypertension 2008, 51:309-318

5. Molojavyi A, Lindecke A, Raupach A, Moellendorf S, Köhrer K, Gödecke A Myoglobin-deficient mice activate a distinct cardiac gene expression program in response to isoproterenol-induced hypertrophy. Physiol Genomics 2010, 41:137-145.

6. Weihua Z, Vijayan E, Mohinder SN, Suresh KG, Naranjan SD: Role of mitogen-activated protein kinase in cardiac hypertrophy and heart failure. Exp Clin Cardiol 2003, 8:173-183.

7. Doggrell SA, Brown L: Rat models of hypertension, cardiac hypertrophy and failure. Cardiovas Res 1998, 39:89-105

8. Vasan RS: Biomarkers of cardiovascular disease: molecular basis and practical considerations. Circulation 2006, 113:2335-2362.

9. Schleicher M, Shepherd BR, Suarez Y, Fernandez-Hernando C, Yu J, Pan Y, Acevedo LM, Shadel GS, Sessa WC: Prohibitin-1 maintains the angiogenic capacity of endothelial cells by regulating mitochondrial function and senescence. J Cell Biol 2008, 180:101-112.

10. Osadchii OE: Cardiac hypertrophy induced by sustained $\beta$ adrenoreceptor activation: pathophysiological aspects. Heart Fail Review 2007, 12:66-86.

11. Ahmad F, Banerjee SK, Lage ML, Huang XN, Smith SH, Saba S, Rager J, Conner DA, Janczewski AM, Tobita K, et al: The role of cardiac troponin T quantity and function in cardiac development and dilated cardiomyopathy. PLoS One 2008, 3:e2642.

12. Laemmli UK: Change of structural protein during the assembly of the head of bacteriophage T4. Nature 1970, 227:680-685.

13. Banerjee SK, Wang DW, Alzamora R, Huang XN, Pastor-Soler NM, Hallows KR, McGaffin KR, Ahmad F: SGLT1, A novel cardiac glucose transporter, mediates increased glucose uptake in PRKAG2 cardiomyopathy. J Mol Cell Cardiol 2010, 49:683-692.

14. Fatkin D, Graham RM: Molecular mechanisms of inherited cardiomyopathies. Physiol Rev 2002, 82:945-980.

15. Wu F, Lee S, Schumacher M, Jun A, Chakravarti S: Differential gene expression patterns of the developing and adult mouse cornea compared to the lens and tendon. Exp Eye Res 2008, 87:214-225.

16. Casey TM, Arthur PG, Bogoyevitch MA: Proteomic analysis reveals different protein changes during endothelin-1- or leukemic inhibitory factor-induced hypertrophy of cardiomyocytes in vitro. Mol Cell Proteom 2005, 4:651-661.

17. Paal SA, Paula LH, Stephen PP, Petros S, Johanna CMS, William JMK, Perry ME, Michael CA: Novel myosin essential light chain mutation causes hypertrophic cardiomyopathy with late onset and low expressivity. Biochem Res Intern 2012, 2012:1-6.

18. Li Y, Wu G, Tang Q, Huang C, Jiang H, Shi L, Tu X, Huang J, Zhu X, Wang H: Slow cardiac myosin regulatory light chain 2 (MYL2) was downexpressed in chronic heart failure patients. Clin Cardiol 2011, 34:30-34.

19. Dhiman M, Zago MP, Nunez S, Amoroso A, Rementeria H, Dousset $P$, Nunez Burgos F, Garg NJ: Cardiac-oxidized antigens are targets of immune recognition by antibodies and potential molecular determinants in chagas disease pathogenesis. PLoS One 2012, 7:e28449.
20. Bowles NE, Bowles KR, Towbin JA: The 'final common pathway' hypothesis and inherited cardiovascular disease. The role of cytoskeletal proteins in dilated cardiomyopathy. Herz 2000, 25:168-175.

21. Collins JF, Pawloski-Dabree C, Davis MG, Ball N, Dorn GW, Walsh RA: The role of cytoskeleton in left ventricular pressure overload hypertrophy and failure. J Mol Cell Cardiol 1996, 28:1435-1443.

22. Azzazy HM, Pelsers MM, Christenson RH: Unbound free fatty acids and heart-type fatty acid-binding protein; diagnostic assays and clinical applications. Clin Chem 2006, 52:19-29.

23. Chen $C Y$, Lee $B C$, Hsu HC, Lin HJ, Chao CL, Lin YH, Ho YL, Chen MF: A proteomic study of the effects of ramipril on post-infarction left ventricular remodeling in the rabbit. Eu J Heart Fail 2008, 10:740-748.

24. Latchman DS: Heat shock proteins and cardiac protection. Cardiovas Res 2001, 51:637-646.

25. Giannessi D, Colotti C, Maltinti M, Ry SD, Prontera C, Turchi S, L'Abbate A, Neglia D: Circulating heat shock proteins and inflammatory markers in patients with idiopathic left ventricular dysfunction: their relationships with myocardial and microvascular impairment. Cell Stress Chaperones 2007, 12:265-274.

26. Dohke T, Wada A, Isono T, Fujii M, Yamamoto T, Tsutamoto T, Horie M: Proteomic analysis reveals significant alternations of cardiac small heat shock protein expression in congestive heart failure. J Cardiac Fail 2006, 12:77-84.

27. Schulz TJ, Westermann D, Isken F, Voigt A, Laube B, Thierbach R, Kuhlow D, Zarse K, Schomburg L, Pfeiffer AF, Tschöpe C, Ristow M: Activation of mitochondrial energy metabolism protects against cardiac failure. Aging (Albany NY) 2010, 2:843-853.

28. Artal-Sanz M, Tavernarakis N: Prohibitin and mitochondrial biology. Trends Endocrinol Metab 2009, 20:394-401.

29. Artal-Sanz M, Tavernarakis N: Opposing function of mitochondrial prohibitin in aging. Aging 2010, 2:1004-1011.

30. Ventura-Clapier R, Garnier A, Veksler V, Joubert F: Review: bioenergetics of the failing heart. Biochim Biophys Acta 1813, 2011:1360-1372.

31. Khatua TN, Padiya R, Karnewar S, Kuncha M, Agawane SB, Kotamraju S, Banerjee SK: Garlic provides protection to mice heart against isoproterenol-induced oxidative damage: role of nitric oxide. Nitric Oxide 2012, 27:9-17.

32. Theiss AL, Idell RD, Srinivasan S, Klapproth JM, Jones DP, Merlin D, Sitaraman SV: Prohibitin protects against oxidative stress in intestinal epithelial cells. FASEB J 2001, 21:1-10.

33. Lord KC, Shenouda SK, Mcllwain E, Charalampidis D, Lucchesi PA, Varner KJ: Oxidative stress contributes to methamphetamine induced left ventricular dysfunction. Cardiovas Res 2010, 87:111-118.

34. Maulik SK, Prabhakar P, Dinda AK, Seth S: Genistein prevents isoproterenolinduced cardiac hypertrophy in rats. Can J Physiol Pharmacol 2012. 90:1117-1125.

doi:10.1186/1479-5876-11-130

Cite this article as: Chowdhury et al:: A proteomic view of isoproterenol induced cardiac hypertrophy: Prohibitin identified as a potential biomarker in rats. Journal of Translational Medicine 2013 11:130.

\section{Submit your next manuscript to BioMed Central and take full advantage of:}

- Convenient online submission

- Thorough peer review

- No space constraints or color figure charges

- Immediate publication on acceptance

- Inclusion in PubMed, CAS, Scopus and Google Scholar

- Research which is freely available for redistribution 